\title{
Case Report \\ Radial Neck Osteotomy for Malunion of Radial Neck Fracture in Childhood
}

\author{
Simon Vandergugten, Serge Troussel, and Bernard Lefebvre \\ Department of Orthopaedic Surgery, Grand Hopital de Charleroi (GHdC), Grand'Rue 3, 6000 Charleroi, Belgium
}

Correspondence should be addressed to Simon Vandergugten; simon.vandergugten@skynet.be

Received 14 April 2015; Accepted 2 August 2015

Academic Editor: Nikolaos K. Kanakaris

Copyright ( $) 2015$ Simon Vandergugten et al. This is an open access article distributed under the Creative Commons Attribution License, which permits unrestricted use, distribution, and reproduction in any medium, provided the original work is properly cited.

\begin{abstract}
In a case of a neglected radial neck fracture in childhood, the management of initial fracture and its complications are subjected to discussion. In children, open reduction should be avoided but an angulation less than $30^{\circ}$ must be obtained. Several techniques exist to manage symptomatic malunion in adults, including resection, prosthesis, and osteotomy. When performing an osteotomy, it is important first to preserve an intact osseous hinge to avoid avascular necrosis and second to align the edge of the radial head articular surface with the lateral edge of the coronoid process, in order to avoid overstuffing elbow joint.
\end{abstract}

\section{Introduction}

Radial neck fracture management remains controversial in children and adults. As there is no consensus, the aim of this report is to discuss the different treatment options in adults suffering from a neglected radial neck fracture having occurred in childhood and resulting in a painful elbow stiffness.

\section{Case Presentation}

A woman aged 33 years has been consulting us for left lateral elbow pain for one year. At the age of 11, she suffered from an isolated radial neck fracture of Grade 4 . She benefited at that time from a percutaneous reduction following Metaizeau technique. Early displacement occurred, leading to a second percutaneous Metaizeau procedure. Secondary displacement occurred again with an angulation of 60 to $70^{\circ}$. Apparent correct elbow ROM pushed the surgeon to not operate on her a third time. Medical records mentioned only a slight supination deficit. Clinical evolution was apparently good until the age of 32, when she started having progressive lateral elbow pain. Clinical examination objectified an elbow flexion at $125^{\circ}$, a $35^{\circ}$ deficit extension, and $10-10^{\circ}$ pronosupination. There was no elbow instability. Her pain was reproduced by writs extension against resistance. The Quick Disabilities of the Arm, Shoulder and Hand (Quick DASH) score was 65.9 (37.5 for work module). Conventional X-ray showed a radial neck malunion of $60^{\circ}$ dorsal angulation on lateral elbow radiographs (Figures 1(a) and 2(a)). There was no chondrolysis on the CT-Scan, but a calcification at the level of the coronoid process of the ulna, which was not a synostosis, was notified. Neither the medical records nor the patient did report elbow dislocation at the time of the primitive traumatism, but the hypothesis of terrible triad elbow (posterior elbow dislocation, coronoid process fracture, and radial head fracture) could not be excluded. However, the elbow was stable at the time of examination and the problem clearly came from the radial neck. After physiotherapists' try for epicondylitis, we suggested that the patient takes a surgical option. The preoperative discussion was about radial head prosthesis, radial head excision, or radial neck osteotomy. Given her young age, we decided to do a radial neck osteotomy with a classical Kocher lateral approach and isolation of posterior interosseous nerve. Radial head cartilage was peroperatively intact, and we could objectify the conflict between anterior margin of the radial head and the coronoid fossa. We performed a radial neck palmar subtraction osteotomy of $60^{\circ}$ on a pronated radius, with preservation of an osseous dorsal hinge (Figure 3). Given the delay since the first surgery, we were not able to remove the $\mathrm{K}$-wire and were forced to cut it at the osteotomy site. 


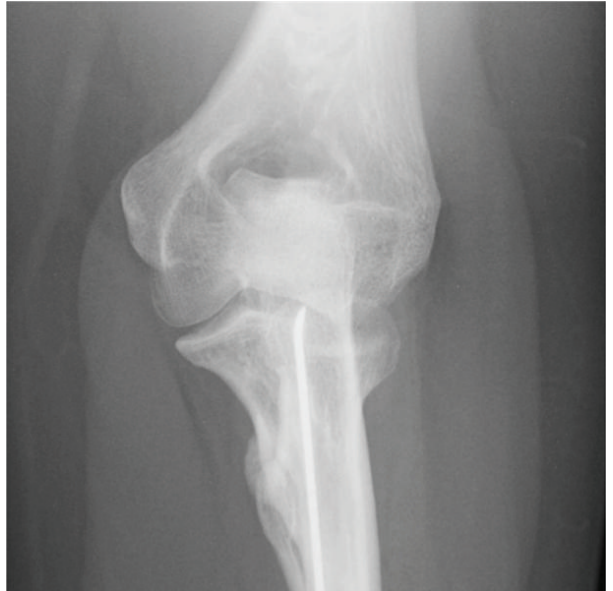

(a)

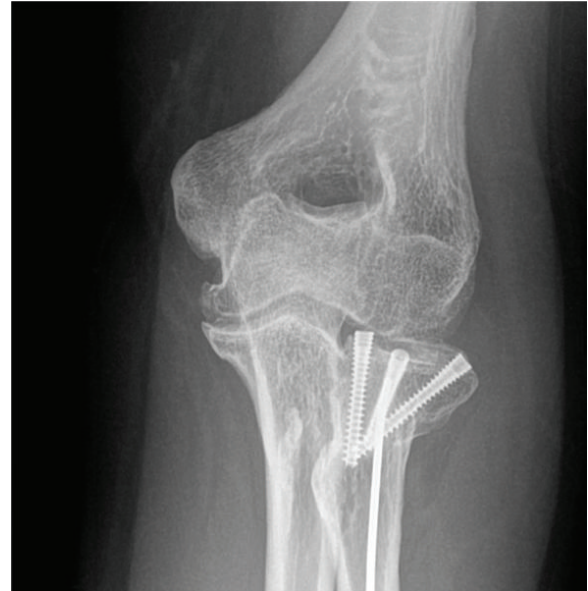

(b)

Figure 1: (a) Preoperative anteroposterior X-ray showing the radial neck malunion. (b) Postoperative anteroposterior X-ray showing the radial head fixation.

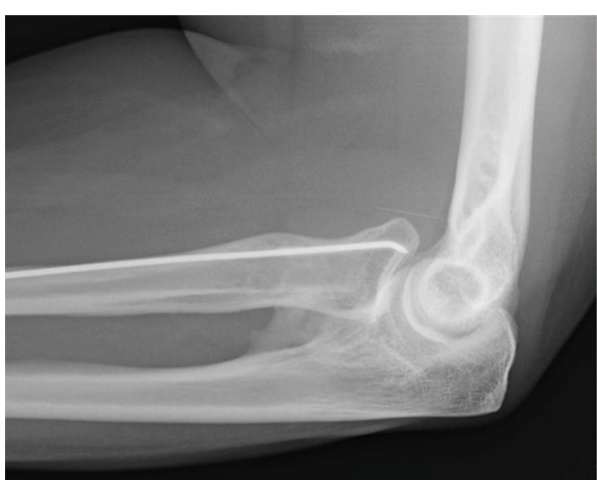

(a)

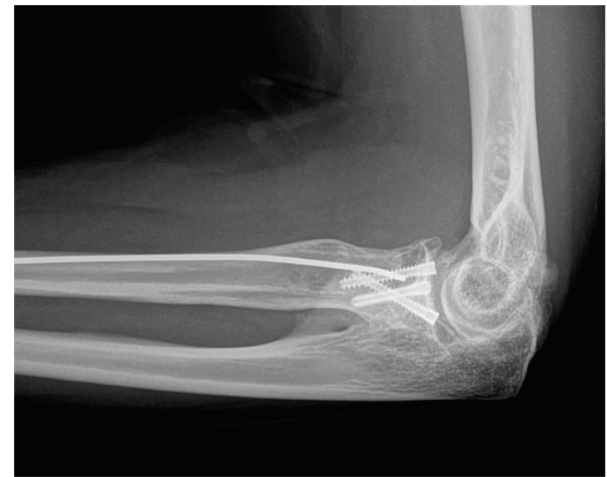

(b)

Figure 2: (a) Preoperative lateral X-ray showing the radial neck malunion of $60^{\circ}$ dorsal angulation. (b) Postoperative X-ray showing the radial neck osteotomy and fixation.

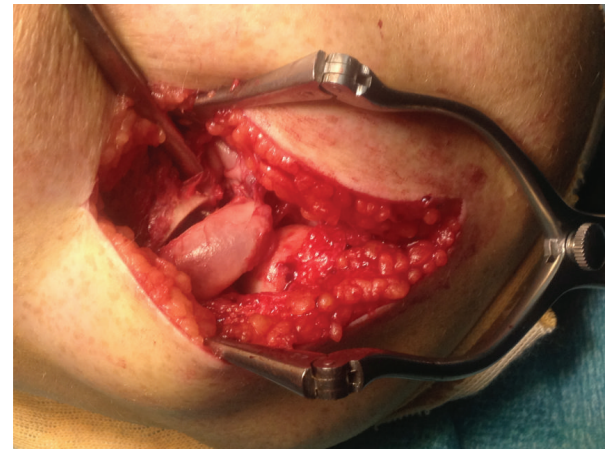

FIGURE 3: Radial neck palmar subtraction osteotomy of $60^{\circ}$ on a pronated radius.

To fix the radial head, we chose 3 intraosseous headless screws (Acutrak 2 Mini Headless Compression Screw System, Acumed LLC, Hillsboro, Oregon, USA) in order to give the maximum ROM possibility to the joint. Peroperatively passive $60^{\circ}-60^{\circ}$ pronosupination led us to leave the ulnar calcification. Elbow was immobilised in a cast for 3 weeks; then, the patient started physiotherapy to improve ROM. Postoperative radiographs showed radial head angulation of $0^{\circ}$ and alignment of the radial head articular surface with the lateral edge of the coronoid process, with slight lateral translation of the radial head (Figures 1(b) and 2(b)). At 6 months, the elbow remained stable and ROM had improved with a complete flexion at $130^{\circ}$, a $15^{\circ}$ deficit extension, and $60-60^{\circ}$ pronosupination without impingement. Lateral elbow pain also improved as well as the Quick DASH score calculated at 4.5 (and 0 for work module).

\section{Discussion}

Management of pediatric radial neck fracture remains controversial [1]. There is no clear consensus about displacement angle acceptance, surgical indication, and the surgical technique to adopt. However, it is admitted that angulation beyond 30 degrees requires treatment and that close reduction techniques must be first tried [1-4]. In case of unstable 
or incomplete close reduction, percutaneous pinning following Metaizeau technique should be performed before open reduction $[1,2,5]$. As salvage procedure, neck osteotomy had been described in children in pain with neglected radial neck fracture [6]. In this case, if an open reduction had been performed after the second displacement in childhood, surgical management might have been avoided at the age of 33.

The most common approach of the radial head and neck is the lateral (posterior) approach of Kocher, passing between the anconeus muscle and the extensor carpi ulnaris muscle (ECU) exposing the proximal radius 3 to $6 \mathrm{~cm}$ before the crossing of the posterior interosseous nerve (PIN) as the forearm is, respectively, moved from supination to pronation $[7,8]$. Annular ligament could then be incised anteriorly to the lateral ulnar collateral ligament (LUCL), which is the posterior part of the lateral collateral ligament, in order to avoid elbow instability [8].

In our case, there were three treatment possibilities. To improve the elbow ROM and hopefully ease the pain, we could simply have resected the radial head. The second possibility was to replace the radial head with metal prosthesis in correct position [9]. The third possibility was to keep the patient's radial head and perform a radial neck correction osteotomy. Regarding the initial treatment of comminuted radial head fracture, it has been proven that internal fixation or radial head replacement had better clinical and functional outcomes than resection [10-12]. This case was different but we straightaway excluded simple resection. The decision between prosthesis and osteotomy was made peroperatively. Radial head cartilage was intact; there was thus absolutely no reason to resect it. Given the $60^{\circ}$ dorsal angulation of radial head articular surface, we decided to perform a palmar subtraction osteotomy of $30^{\circ}$ in order to obtain an articular surface perpendicular to the radial shaft axis. In order to move away PIN, osteotomy was done on a pronated radius [7].

Anatomical studies have proven that the blood supply to the radial head is tenuous and mainly periosseous, coming from a pericervical ring around the radial neck, resulting from the union of branches of radial recurrent artery laterally, periosseous branches of ulnar artery medially, and interosseous recurrent artery posteriorly $[13,14]$. That is why it is important to preserve an osseous and periosseous hinge in order to avoid avascular necrosis of the radial head.

To assess the correct height of the radial head articular surface, we depended on reference points for radial head prosthesis size. To avoid overstuffing the elbow joint, CTScan study suggested just to align the edge of the radial head articular surface with the lateral edge of the coronoid process articular surface which is easily seen with the used surgical approach [15].

Several methods exist to fix the radial head, as in the case of radial neck fracture: crossed K-wires, antegrade interfragmentary screw, and anatomical T-plate with compression or locked screws. Biomechanical studies may attest an advantage of the interfragmentary screw in terms of rigidity in bending and torsion [16], whereas a recent review brings similar results of different types of fixation devices [12]. It has been proven that plate fixation leads to higher destruction of periosseous vascularisation than screw [13]. In addition, we thought that a T-plate could increase the elbow stiffness and would necessitate an additional removing surgery.

\section{Conflict of Interests}

The authors declare that there is no conflict of interests regarding the publication of this paper.

\section{References}

[1] R. M. Zimmerman, L. A. Kalish, M. T. Hresko, P. M. Waters, and D. S. Bae, "Surgical management of pediatric radial neck fractures," The Journal of Bone \& Joint Surgery-American Volume, vol. 95, no. 20, pp. 1825-1832, 2013.

[2] T. E. Radomisli and A. L. Rosen, "Controversies regarding radial neck fractures in children," Clinical Orthopaedics and Related Research, pp. 30-39, 1998.

[3] S. D’Souza, R. Vaishya, and L. Klenerman, "Management of radial neck fractures in children: a retrospective analysis of one hundred patients," Journal of Pediatric Orthopaedics, vol. 13, no. 2, pp. 232-238, 1993.

[4] E. C. R. Merchan, "Displaced fractures of the head and neck of the radius in children: open reduction and temporary transarticular internal fixation," Orthopedics, vol. 14, no. 6, pp. 697-700, 1991.

[5] J.-P. Metaizeau, P. Lascombes, J.-L. Lemelle, D. Finlayson, and J. Prevot, "Reduction and fixation of displaced radial neck fractures by closed intramedullary pinning," Journal of Pediatric Orthopaedics, vol. 13, no. 3, pp. 355-360, 1993.

[6] D. Ceroni, J. Campos, A. Dahl-Farhoumand, J. Holveck, and A. Kaelin, "Neck osteotomy for malunion of neglected radial neck fractures in children: a report of 2 cases," Journal of Pediatric Orthopaedics, vol. 30, no. 7, pp. 649-654, 2010.

[7] R. P. Calfee, J. M. Wilson, and A. H. W. Wong, "Variations in the anatomic relations of the posterior interosseous nerve associated with proximal forearm trauma," The Journal of Bone and Joint Surgery-American Volume, vol. 93, no. 1, pp. 81-90, 2011.

[8] O. Barbier, "Voies d'abord des deux os de l'avant-bras," Techniques Chirurgicales-Orthopédie-Traumatologie, pp. 44-340, 2010.

[9] G. I. Bain, N. Ashwood, R. Baird, and R. Unni, "Management of mason type-III radial head fractures with a titanium prosthesis, ligament repair, and early mobilization," The Journal of Bone \& Joint Surgery Series A, vol. 87, no. 1, pp. 136-147, 2005.

[10] M. Ikeda, K. Sugiyama, C. Kang, T. Takagaki, and Y. Oka, "Comminuted fractures of the radial head: comparison of resection and internal fixation," The Journal of Bone and Joint SurgeryAmerican Volume, vol. 87, no. 1, pp. 76-84, 2005.

[11] G. Zarattini, S. Galli, M. Marchese, L. D. Mascio, and U. E. Pazzaglia, "The surgical treatment of isolated mason type 2 fractures of the radial head in adults: comparison between radial head resection and open reduction and internal fixation," Journal of Orthopaedic Trauma, vol. 26, no. 4, pp. 229-235, 2012.

[12] Y. Gao, W. Zhang, X. Duan et al., "Surgical interventions for treating radial head fractures in adults," The Cochrane Database of Systematic Reviews, no. 5, Article ID CD008987, 2013.

[13] T. C. Koslowsky, S. Schliwa, and J. Koebke, "Presentation of the microscopic vascular architecture of the radial head using 
a sequential plastination technique," Clinical Anatomy, vol. 24, no. 6, pp. 721-732, 2011.

[14] K. Yamaguchi, F. A. Sweet, R. Bindra, B. F. Morrey, and R. H. Gelberman, "The extraosseous and intraosseous arterial anatomy of the adult elbow," The Journal of Bone \& Joint Surgery Series A, vol. 79, no. 11, pp. 1653-1662, 1997.

[15] J. N. Doornberg, D. S. Linzel, D. Zurakowski, and D. Ring, "Reference points for radial head prosthesis size," Journal of Hand Surgery, vol. 31, no. 1, pp. 53-57, 2006.

[16] J. T. Capo, D. Svach, J. Ahsgar, N. S. Orillaza, and C. T. Sabatino, "Biomechanical stability of different fixation constructs for ORIF of radial neck fractures," Orthopedics, vol. 31, no. 10, 2008. 


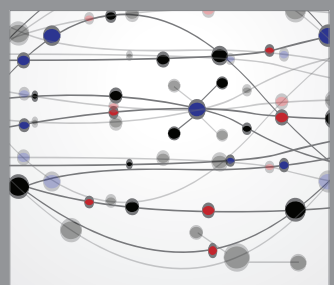

The Scientific World Journal
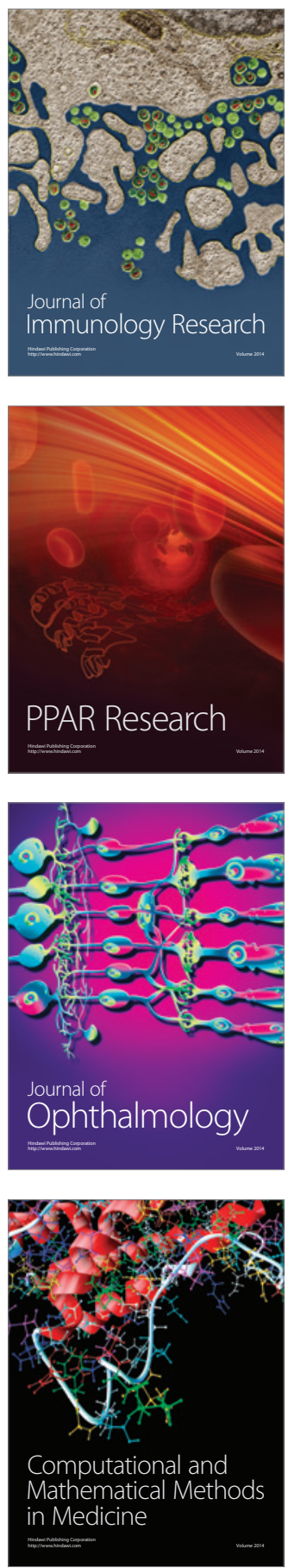

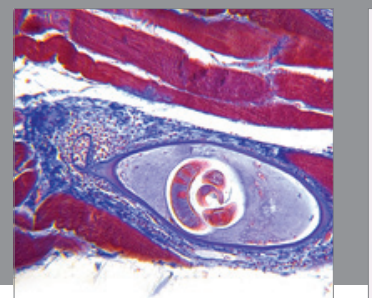

Gastroenterology

Research and Practice
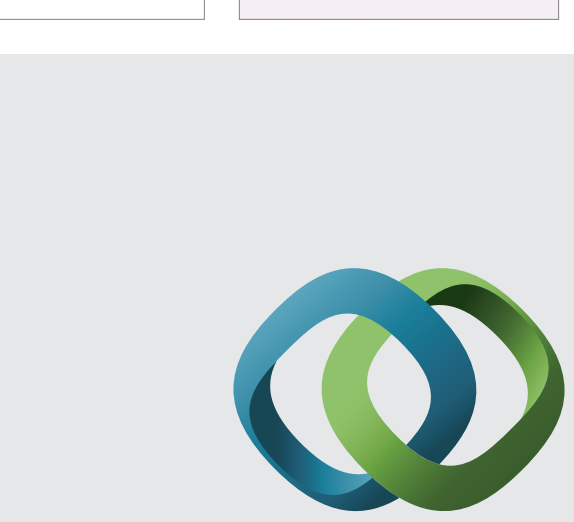

\section{Hindawi}

Submit your manuscripts at

http://www.hindawi.com
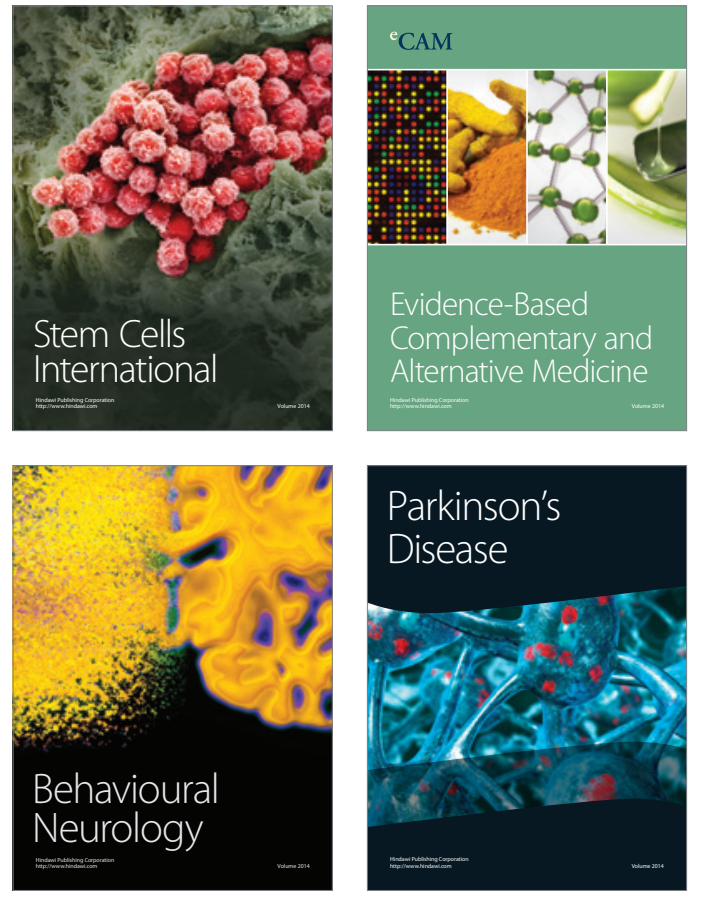
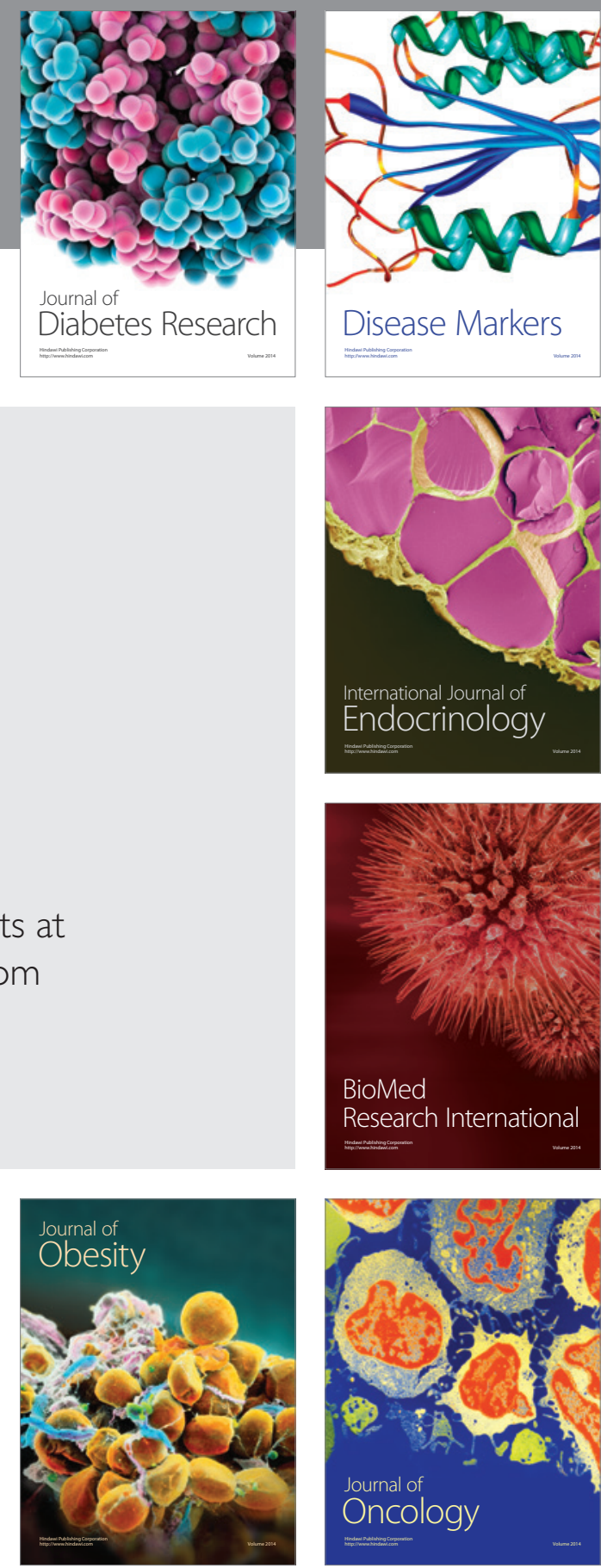

Disease Markers
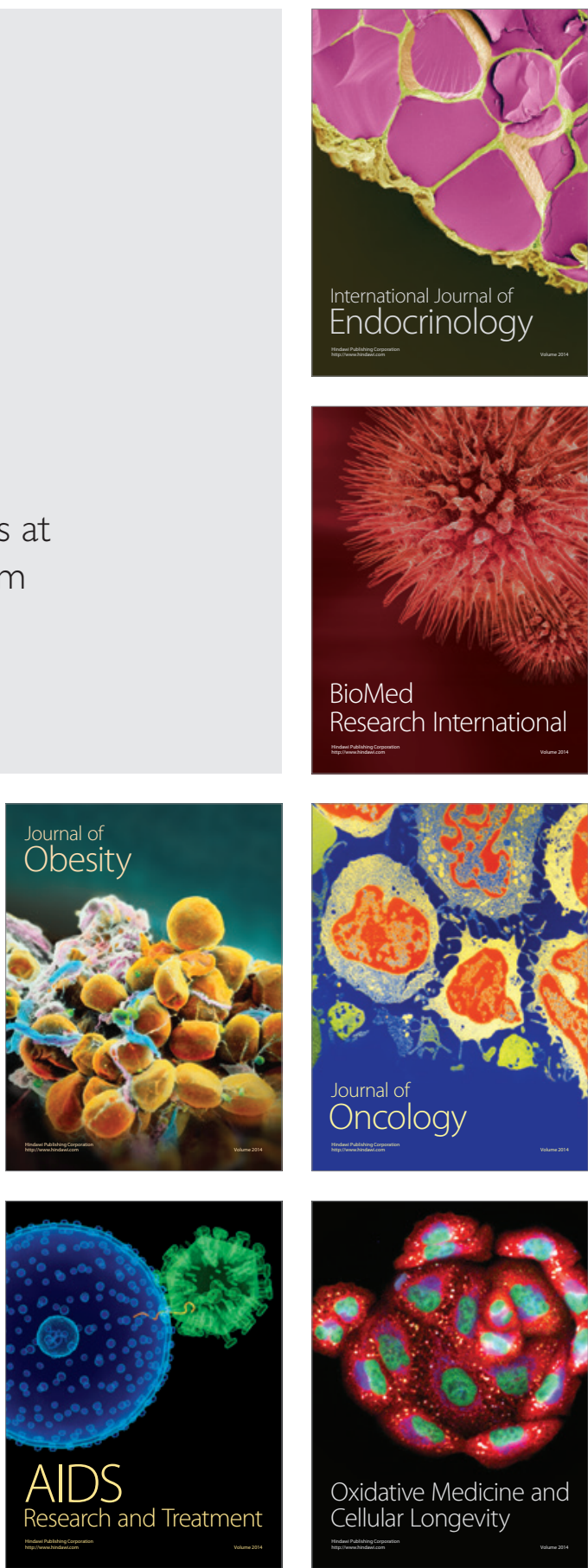